\title{
Single-dose radiosurgical treatment for hepatic metastases - therapeutic outcome of 138 treated lesions from a single institution
}

Daniel Habermehl ${ }^{1,3^{*}}$, Klaus K Herfarth', Justo Lorenzo Bermejo ${ }^{2}$, Holger Hof ', Stefan Rieken ${ }^{1}$, Sabine Kuhn ${ }^{1}$, Thomas Welzel', Jürgen Debus ${ }^{1}$ and Stephanie Combs $^{1}$

\begin{abstract}
Background: Local ablative therapies such as stereotactically guided single-dose radiotherapy or helical intensitymodulated radiotherapy (tomotherapy) with high single-doses are successfully applied in many centers in patients with liver metastasis not suitable for surgical resection. This study presents results from more than 10 years of clinical experience and evaluates long-term outcome and efficacy of this therapeutic approach.

Patients and methods: From 1997 to 2009 a total of 138 intrahepatic tumors of 90 patients were irradiated with single doses of 17 to 30 Gy (median dose 24 Gy). Median age of the patients was 64 years (range 31-89 years). Most frequent underlying tumor histologies were colorectal adenocarcinoma (70 lesions) and breast cancer (27 lesions). In 35 treatment sessions multiple targets were simultaneously irradiated (up to four lesions at once). Local progression-free (PFS) and overall survival (OS) after treatment were investigated using uni- and multiple survival regression models.
\end{abstract}

Results: Median overall survival of all patients was 24.3 months. Local PFS was 87\%, 70\% and 59\% after 6, 12 and 18 months, respectively. Median time to local progression was 25.5 months. Patients with a single lesion and no further metastases at time of RT had a favorable median PFS of 43.1 months according to the Kaplan-Meier estimator. The type of tumor showed a statistical significant influence on local PFS, with a better prognosis for breast cancer histology than for colorectal carcinoma in uni- and multiple regression analysis $(p=0.05)$. Multiple regression analysis revealed no influence of planning target volume (PTV), patient age and radiation dose on local PFS. Treatment was well tolerated with no severe adverse events.

Conclusion: This study confirms safety of SBRT in liver lesions, with 6- and 12 months local control of $87 \%$ and $70 \%$. The dataset represents the clinical situation in a large oncology setting, with many competing treatment options and heterogeneous patient characteristics.

\section{Introduction}

Liver metastases frequently occur in patients with cancer, with the incidence varying depending on the underlying type of disease. The most frequent underlying tumor is localized in the gastrointestinal tract, predominantly colorectal cancer; in these patients approximately $25 \%$ of the patients present with liver metastases at

\footnotetext{
* Correspondence: daniel.habermehl@med.uni-heidelberg.de

${ }^{1}$ Department of Radiation Oncology, University Hospital Center Heidelberg,

INF 400, Heidelberg 69120, Germany

${ }^{3}$ Klinik für Radioonkologie, University of Heidelberg, INF 400 69120,

Heidelberg, Germany

Full list of author information is available at the end of the article
}

primary diagnosis, and around 50\% have been reported to develop liver lesions within 5 years from initial diagnosis [1]. In the past, radiation therapy played only a minor role in the treatment of liver metastases, due to the low tolerance of the normal liver tissue to radiation [2]. Radiation-induced side effects, namely RILD (Radiation Induced Liver Disease) were expected and thus RT was used only in rare cases. Therefore, surgery or other locally ablative alternatives were preferred in these patients.

In case of oligometastasis to the liver surgical resection is still the standard treatment, and locally ablative treatments are often held back and are applied in heavily

\section{Biomed Central}


pre-treated patients with multiple lesions to the liver. Considering the outcome of patients with liver metastases, outcome substantially depends on cancer histology: In patients with colorectal carcinoma survival rates of up to $64 \%$ five years after intervention can be achieved after surgical resection [3]. A recent metaanalysis on surgical resection of liver metastases derived from breast cancer describes a median overall survival of 40 months and a median 5-year survival rate of $40 \%$ in a selected patient cohort [4]. However, in a substantial number of patients, unfortunately, liver lesions are not amenable to resection, or patients suffer from severe comorbidities or present with reduced overall performance status; thus, surgical intervention may not be possible in these patients $[5,6]$.

Locally ablative treatments such as radiofrequency ablation (RFA), percutaneous ethanol injection (PEI) or transcatheter arterial chemoembolization (TACE) are therefore widely accepted alternative treatment approaches with promising local control rates [7-9]. Nevertheless, minimal-invasive techniques still have major limitations such as tumor size and localization, and the individual tumor blood supply. In many cases, tumors still recur after a few months [10].

Modern radiation techniques have modified the role of radiation therapy in this clinical situation and have led to an establishment of this treatment modality in liver cancer patients. Thus, application of even high tumoricidal doses can be applied safely and non-invasively by stereotactic body radiotherapy (SBRT), intensity-modulated RT (IMRT) or even particle beam therapy (PBT) [11-21]. Many reports over the last years have shown favourable local control rates after radiosurgery or hypofractionated $\mathrm{RT}$ in liver metastases or even small primary liver tumors with an advantageous toxicity profile [22-29].

The present study reports long-term follow-up of a mono-institutional experience including 90 patients with 138 hepatic tumors treated at our institution.

\section{Patients and methods}

\section{Patients and treatment}

From 1997 to 2009 one hundred thirty-eight intrahepatic tumors from ninety patients were irradiated with total doses of 17 to 30 Gy (median dose 24 Gy) using stereotactic body radiotherapy (SBRT) or helical intensity-modulated radiotherapy (tomotherapy). Generally, following our institutional guidelines, these patients are treated with radiosurgical approaches. The decision on whether RT was performed by SBRT or HT (helical tomotherapy) was made according to current treatment capacities in our institution and had no medical or dosimetric reasons.

Median age was 64 years (range 31-89 years). A total of 126 lesions were irradiated using SBRT and 12 lesions using tomotherapy. Applied single fraction doses varied from 17 to 30 Gy and in most treatments the following doses were prescribed: 24 Gy (41 pts.), 20 Gy (37 pts.), 28 Gy (24 pts.) and 22 Gy (14 pts.) (Table 1).

In most cases dose was prescribed to the $80 \%$-isodose in case of single-dose RT. In some cases the applied dose was prescribed to the dose maximum when appropriate, depending on the size of the lesion, proximity to organs at risk such as the intestines, or proximity to other radiation treatment volumes. In 28 cases two lesions were irradiated in one session, six patients received single-dose RT to a PTV encompassing three different lesions and

\section{Table 1 Patient and treatment details}

\begin{tabular}{|c|c|}
\hline Total number of analyzed patients/lesions & 90 patients/138 lesions \\
\hline \multicolumn{2}{|l|}{ Gender } \\
\hline Male & 47 patients, 75 lesions \\
\hline Female & 43 patients, 63 lesions \\
\hline \multicolumn{2}{|l|}{ Age $[y]$} \\
\hline Median, range [years] & $64(31-89)$ \\
\hline \multicolumn{2}{|l|}{ Radiation technique [number of lesions] } \\
\hline Single-dose (radiosurgery) & 138 \\
\hline Stereotactic Body RT (SBRT) & 126 \\
\hline Helical IMRT (tomotherapy) & 12 \\
\hline \multicolumn{2}{|l|}{ Treatment in 1 session } \\
\hline One lesion & 62 \\
\hline Two lesions & 28 \\
\hline Three lesions & $6^{*}$ \\
\hline Four lesions & 1 \\
\hline \multicolumn{2}{|l|}{ RT Dose } \\
\hline Median, range [Gy] & $24(17-30)$ \\
\hline Applied doses & Number \\
\hline 17-20 Gy & 43 \\
\hline $21-25$ Gy & 60 \\
\hline 26-30 Gy & 35 \\
\hline Previous treatment & Number of patients \\
\hline Surgery & 18 \\
\hline RFA & 3 \\
\hline LITT & 3 \\
\hline TACE & 1 \\
\hline Other metastases at time of RT & Number \\
\hline None & 53 \\
\hline History of metastases & 48 \\
\hline Simultaneous metastases & 37 \\
\hline Planning Target Volume (median, range) & $62 \mathrm{ml}(11-333 \mathrm{ml})$ \\
\hline Liver volume & $1483 \mathrm{ml}$ (range 982-2647 ml) \\
\hline
\end{tabular}

*1 patient with three lesions included in 1 target volume.

$R T$ radiotherapy, $L M$ liver metastasis, RFA radiofrequency ablation, TACE transcatheter arterial chemoembolization, $L I T T$ laser-induced thermotherapy. 
in one patient four lesions were treated simultaneously. Six patients received more than one radiation course because of recurrent lesions during observation period. Median irradiated planning target volume was $62 \mathrm{ml}$ (range 11-333 $\mathrm{ml}$ ) and average normal liver volume was $1483 \mathrm{ml}$ (range 982-2647 ml) (Table 1).

The most frequent primary tumor site was colorectal adenocarcinoma (70 pts.), followed by breast cancer (27 pts.), pancreatic adenocarcinoma (11 pts.) and ovarian cancer (7 pts.) (Table 2).

\section{Patient immobilization and treatment planning}

Patients were immobilized as described previously $[22,30]$. In brief, patients were immobilized using an individually shaped vacuum pillow and an abdominal compression to reduce the liver movement. A contrast agent enhanced CT scan and a 4D-CT series for quantifying liver motion was acquired for treatment planning.

The extracranial stereotactic set-up has been developed at the German cancer research center ( $\mathrm{dkfz}$ ) and is commercially available (Leibinger, Freiburg, Germany). The patient is positioned in an individually shaped vacuum pillow (Brandis Medizintechnik, Weinheim, Germany). The intra-corporal movement of the liver was reduced by epi-gastrical compression using a triangular Plexiglas plate. Fixation of the plate is performed by two bars, which are firmly attached to the metal arch. A Siemens somatom plus 4. (Siemens, Erlangen, Germany) was used for treatment planning. A spiral CT scan with $5 \mathrm{~mm}$ slice thickness and $500 \mathrm{~mm}$ field of view was

Table 2 Primary tumor sites

\begin{tabular}{ll}
\hline Primary tumor site & $\begin{array}{l}\text { Number of treated liver } \\
\text { metastases }\end{array}$ \\
\hline TOTAL & $\mathbf{1 3 8}$ \\
Colorectal adenocarcinoma & 70 \\
Adenocarcinoma of the breast & 27 \\
Pancreatic adenocarcinoma & 11 \\
Ovarian cancer & 7 \\
Lung cancer & 6 \\
Gastric cancer & 3 \\
Sarcoma & 2 \\
Cholangiocarcinoma & 2 \\
Esophagus & 2 \\
Endometrium & 2 \\
Lymphoma & 1 \\
Renal Cell Cancer & 1 \\
Cervival cancer & 1 \\
Adenoid-cystic carcinoma & 1 \\
Anal Cancer & 1 \\
\hline
\end{tabular}

performed which included the localization system. The patients were advised to breathe normally during the scanning time without taking deep breaths.

On the treatment day patients were repositioned in the above mentioned setting using pen marks and another control CT scan. Until the year 2003, CT imaging was performed offline, and, if positioning was adequate, patients were brought to the linear accelerator (LINAC) using an individual shuttle system leaving the patient in the vacuum bag/abdominal press fixation. In recent years (2004-2009), LINACs (e.g. Siemens Artiste, Siemens Healthcare, Erlangen, Germany) were equipped with on-board imaging as, e.g. in case of tomotherapy, a combination of the $6 \mathrm{MeV}$ LINAC with CT imaging.

Target and OAR contouring was performed using Siemens Dosimetrist and Oncologist software, and inverse treatment planning was conducted applying the Hi-ART Tomotherapy planning software (TomoTherapy Inc., Madison, WI, USA). Dose constraints for adjacent organs at risk and the liver were used accroding to Emami et al. and Dawson et al. [31,32].

\section{Follow-up}

Median follow-up was 21.7 months (range 1.6 151.8 months). Local failure patterns were determined by follow-up clinical examination, radiographic imaging including CT- and MRI scans as well as ultrasound. Overall survival (OS) was calculated from the treatment day on. Local Progression-free survival was determined as the period between the treatment day and appearance of any local recurrence; data was censored in case of death without progression or last follow-up in patients without progression. Univariate survival curves were plotted based on the Kaplan-Meier method. In addition to univariate analyses, multiple regression relying on a proportional hazard (Cox) model was performed. Statistical calculations were implemented using SAS version 9.2 (SAS Institute, Cary, NC, USA), and survival curves were plotted using R 2.11.0 (www.rproject.org).

\section{Results}

\section{Overall survival (OS)}

The median OS for all patients was 24.3 months (95\%CI 20.8 - 28.6 months), the corresponding survival curves are represented in Figure 1. Relevant factors associated with a poor prognosis according to univariate analyses were the primary site of the tumor $(\mathrm{HR}=2.56$ for 'other' compared to colorectal tumors, global $\mathrm{p}=$ $0.002)$, the number of lesions $(\mathrm{p}<0.001)$ and a late calendar year (2001-2009) at diagnosis $(\mathrm{HR}=1.52, \mathrm{p}=$ 0.04). Multiple regression survival analysis consistently pointed out to a poorer prognosis of patients with metastases outside the liver at the time of RT or a history of metastasis $(\mathrm{HR}=2.64, \mathrm{p}=0.003)$, and also the number 


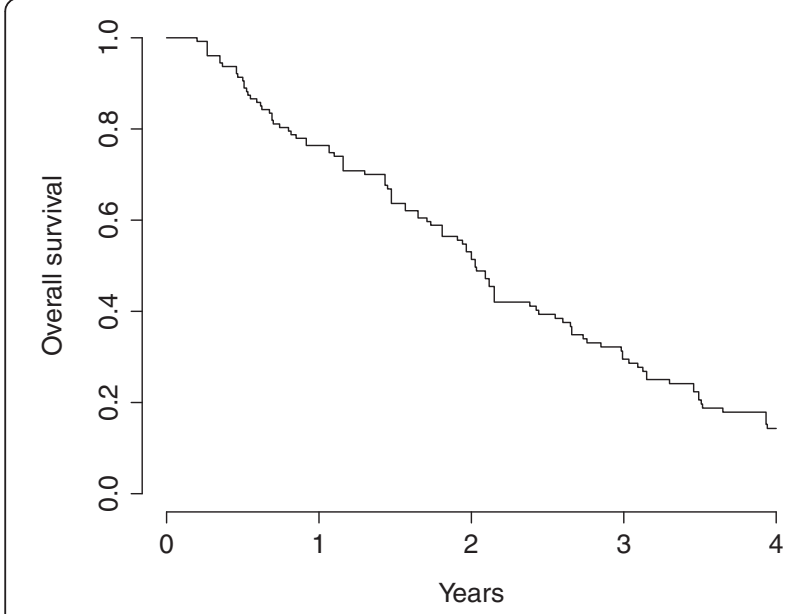

Figure 1 Kaplan-Meier overall survival curve for all patients.

of simultaneously irradiated lesions showed an effect on OS $(\mathrm{p}=0.02)$. Patients with a primary tumor histology of colorectal cancer had a better prognosis than other histologies $(\mathrm{HR}=4.39, \mathrm{p}=0.0009)$.

\section{Progression-free survival}

The proportions of lesions without local progression after 6, 12 and 18 months were $87.3 \%, 69.9 \%$ and 58.5\% respectively. The median time to local progression was 25.5 months for the entire patient group (Figure 2). The number of metastases (one vs. multiple) that were included in one or more PTVs or were irradiated simultaneously during one session showed no influence on local control $(p=0.76)$. The type of tumor showed an influence on the local control of irradiated metastases, lesions from patients suffering from colorectal carcinoma ('crc') showed a poorer control than those from patients affected by breast cancer ('bc') in univariate and multiple

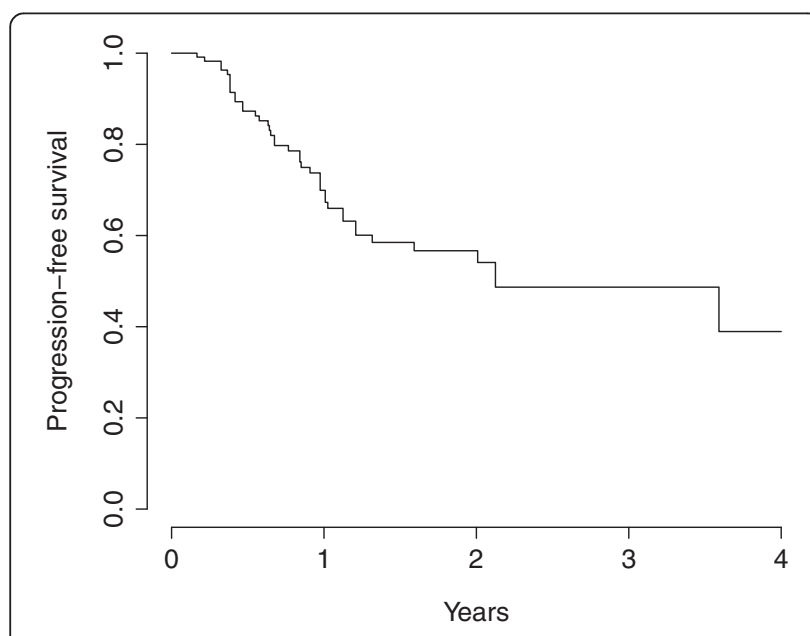

Figure 2 Local progression-free time (PFS) of lesions. regression analyses (multivariate HR for breast cancer $0.15, \mathrm{p}=0.05)$. The survival curve on Figure 3 suggest that, after single-dose SBRT, lesions in patients with metastasis from breast cancer show a slower local progression.

The effects on progression of planning target volume (PTV) (11-59 $\mathrm{ml}$ or $60-333 \mathrm{ml})$, patients' age (31-59 or 60-89 years), primary tumor site (colorectal cancer, breast cancer, other), number of metastases (singular vs. multiple) and applied radiation dose (17-22 Gy, 2324 Gy, >25 Gy) did not reach statistical significance according to multiple Cox regression. Patients with a single lesion had a median PFS of 43.1 months according to the Kaplan-Meier estimator, but survival differences between patients with single lesions and those patients with other lesions than the treated ones at time of RT did not reach statistical significance according to uniand multiple regression models (univariate: $\mathrm{p}=0.32$, multivariate: $\mathrm{p}=0.41$ ).

\section{Toxicity}

Overall tolerance of RT was high. Radiation side effects were mild and included in some cases mild fever, nausea, chills, loss of appetite and transient elevation of alkaline phosphatase. No Radiation-induced-liver disease (RILD) was observed in the entire patient group.

\section{Discussion}

In the present work we report our long-term follow up of highly conformal radiation therapy in patients with liver metastases delivered as radiosurgery. In this cohort of 90 patients with 138 metastatic lesions, local control was nearly $90 \%$ after six months. The main underlying tumor type was colorectal cancer, followed by breast

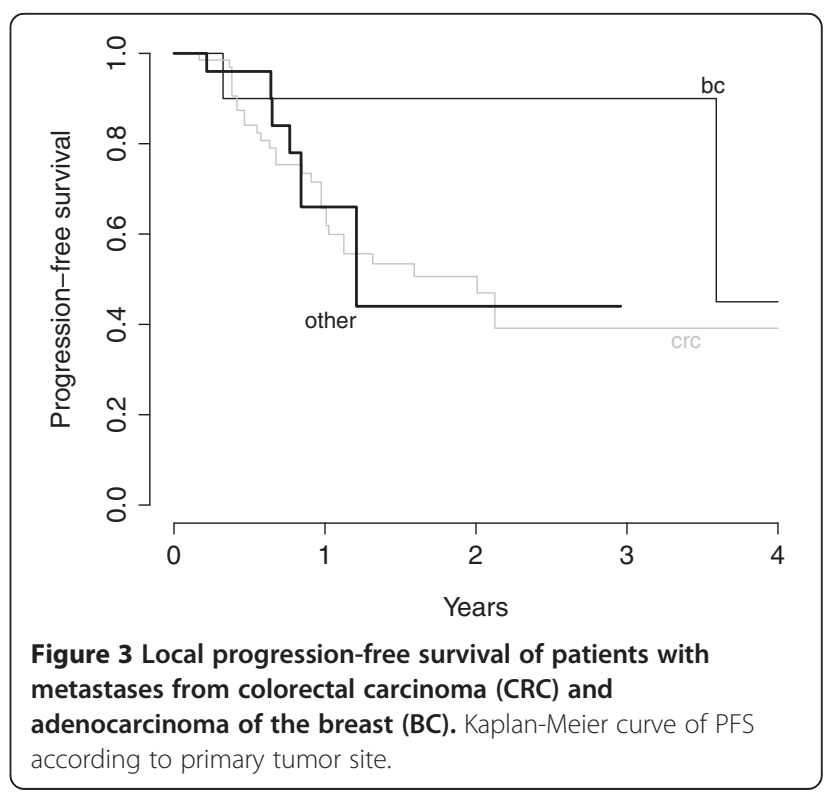


cancer. Overall survival in the whole group was 24.3 months, and prognostic factors included primary tumor histology. In our analysis of this patient group with a wide variety of different underlying primary tumors and different systemic and local pre-treatments, local control rates within the range of published data (Table 3) can be achieved with single fraction RT even in case of multiple target lesions.

In general, the development of SBRT or other techniques to deliver precisely high local doses have changed the paradigm for radiation therapy in the multimodal treatment of liver metastases. Radiation tolerance of liver normal tissue is limited in contrast to the high local doses required for long-term local control of metastatic lesions. The dose-limiting toxicity of the whole liver is RILD, which in the early days was named radiation hepatitis [33]. It is characterized by a rise in liver enzymes, namely alkaline phosphatase, and ascites; histopathologically, venous occlusion is the most predominant change in pathological specimens [34].

Respecting individual target volumes and dosing schemes, toxicity rates can be minimized, even for larger volumes. In contrast to primary liver cancer, liver metastases most commonly occur in non-cirrhotic livers, and the most predominant toxicity to radiation will be RILD; however, adhering to established dose constraints of normal liver tissue, i.e. keeping below 30 Gy median liver dose in conventional fractionation [31] or application of less than 15 Gy to $700 \mathrm{ml}$ of healthy liver tissue, this may be securely avoided. Most of the studies report mild adverse events such as transient elevation of alkaline phosphatase or fatigue symptoms, toxicity grade III or higher (CTCAE) is very uncommon and occurs only when high doses are applied to the small bowel or to large volumes of the liver [35]. However in our analysis no higher grade toxicities were recorded, especially no clinically apparent RILD. Nevertheless a major weakness of this work remains the documentation of detailled toxicity aspects according to the Common Toxicity Criteria for Adverse Events (CTCAE) because of the retrospective nature of the study. The available medical records and documents did not point out to higher grade of clinically relevant adverse events, e. g. gastro-intestinal ulceration. Therefore we refer to published reports on comparable radiosurgery treatment protocols where mostly mild toxicities are observed and higher grad toxicities are surely very rare events (see Table 3).

Median overall survival of patients with untreated liver metastasis differs among histologies of the primary tumor between 5 and 19 months [36,37]. After surgical resection a five-year OS of $64 \%$ can be achieved [3]. Patients should only undergo resection if clear resection margins can be achieved (R0-resection), because positive margins (including R1- and R2-resections) are associated with a poor five-year OS of $0 \%$ in many case series $[38,39]$. While surgery is the mainstay of treatments, substantial numbers of patients are not amenable for surgical resection, often for underlying medical conditions $[5,6]$. Therefore a current need for local ablative treatment options in liver metastasis is evident. With the advancing techniques of SBRT and other elaborate modalities allowing for precise local high dose deposition, several institutions have treated a large number of patients with liver metastases, either applying radiosurgery or hypofractionated regimens (Table 3). Survival of patients in our analysis is relatively good and in the range of the above mentioned group of patients undergoing surgery. Median OS was 24.3 months and depending on the prognostic subgroup (breast cancer histology, no further metastases at time of RT) median local PFS is even higher.

Recently a phase-I clinical trial examining a dose escalation with single-fraction SBRT from initially 18 to 30 Gy in 19 patients with hepatic metastases has shown efficacy without reporting dose-limiting toxicity [21]. Risk for local failure 12 months after treatment was $23 \%$. Table 3 provides a summary of the largest studies on SBRT of liver metastases, including single-fraction RT as well as the more commonly used 3-5 fraction protocols. Overall, local control ranges between 70 and $95 \%$ at one year, depending on the series; however, only few studies have been conducted using a formal dose-escalation part. Rusthoven and colleagues performed a multicentric phase I/II clinical trial starting with 36 Gy at 3 fractions, and dose was escalated in 6 Gy increments up to a defined maximum of 60 Gy [11]. Tumor volume was a strong predictor for local control, with smaller lesions showing a longer tumor control. Colleagues from the University of Texas Southwestern reported on a Phase I study starting with 30 Gy in 3 fractions up to 60 Gy in 5 fractions [28]. An argument for the five-fraction scheme was the potential to treat lesions in close vicinity to periportal biliary structures avoiding radiation-induced toxicity with lower single doses. A third dose-escalation study was published by Goodman et al. and was phase I dose-escalation single-fraction trial including not only patients with liver metastases, but also with intrahepatic cholangiocarcinoma [21]. Dose escalation was conducted in 4 Gy treatment groups from 18-30 Gy, in a single fraction. Also in this study, no dose limiting side effects were observed. A recent mono-institutional analysis of heavily local and systemic pre-treated patients with liver tumors undergoing cyber knife ${ }^{\circledR}$-based RT showed the feasibility and efficacy of 3-5 fraction regimens with doses of $\mathrm{BED} \geq 79.2$ Gy10 $=66$ Gy EQD2 [40]. In this setup remarkable LC rates of up to $74 \%$ after 2 years can achieved with doses of BED $\geq 100$ Gy10. But there are also some reports indicating higher local control rates of 
Table 3 Literature overview

\begin{tabular}{|c|c|c|c|c|c|c|c|}
\hline Author & Year & $\begin{array}{l}\text { Primary } \\
\text { tumour }\end{array}$ & $\begin{array}{l}\text { Number of } \\
\text { patients }\end{array}$ & $\begin{array}{l}\text { Number of } \\
\text { fractions }\end{array}$ & Overall dose & Local control & Details \\
\hline Herfarth et al. [14] & 2001 & $\begin{array}{l}\text { Mets and } \\
\text { PLC }\end{array}$ & 56 & 1 & $14-26$ Gy & $67 \%$ after 18 months & \\
\hline \multirow[t]{3}{*}{ Wulf et al. [15] } & \multirow[t]{3}{*}{2001} & \multirow[t]{3}{*}{$\begin{array}{l}\text { Mets and } \\
\text { PLC }\end{array}$} & \multirow[t]{3}{*}{56} & \multirow[t]{3}{*}{3} & $\begin{array}{l}27 \text { pts. } 3 \times 10 \text { Gy } \\
1 \text { pt. } 4 \times 7 \text { Gy }\end{array}$ & \multirow[t]{3}{*}{$\begin{array}{l}\text { 61\% after } 2 \text { years PLT: } 100 \% \text { after } \\
\text { median f/u } 15 \text { mo. }\end{array}$} & \\
\hline & & & & & $\begin{array}{l}19 \text { pts. } 3 \times 12-12 \\
.5 \text { Gy }\end{array}$ & & \\
\hline & & & & & 1 pt. 1 × 26 Gy & & \\
\hline \multirow[t]{2}{*}{ Schefter et al. [16] } & \multirow[t]{2}{*}{2005} & \multirow[t]{2}{*}{ Mets } & \multirow[t]{2}{*}{18} & \multirow[t]{2}{*}{3} & 9 Pts.: 36 Gy & \multirow[t]{2}{*}{ Not reported } & \multirow[t]{2}{*}{ Phase-I study } \\
\hline & & & & & 9 Pts.: 60 Gy & & \\
\hline Hoyer et al. [17] & 2006 & Mets & 44 & 3 & 45 & Not reported & $\begin{array}{l}\text { Phase-II study, } \\
\text { Liver-specific data } \\
\text { not reported }\end{array}$ \\
\hline $\begin{array}{l}\text { Kavanagh et al. } \\
\text { [18] }\end{array}$ & 2006 & Mets & 36 & 3 & 60 Gy & $93 \%$ after 18 months & Phase-I/II study \\
\hline \multirow{2}{*}{$\begin{array}{l}\text { Mendez-Romero } \\
\text { et al. [19] }\end{array}$} & \multirow[t]{2}{*}{2006} & \multirow{2}{*}{$\begin{array}{l}\text { Mets and } \\
\text { PLC }\end{array}$} & \multirow[t]{2}{*}{45} & \multirow[t]{2}{*}{3} & $37.5 \mathrm{~Gy}$ & \multirow[t]{2}{*}{$82 \%$ after 2 years } & \multirow[t]{2}{*}{ Phase-1/II study } \\
\hline & & & & & $\begin{array}{l}\text { (also } 5 \times 5 \mathrm{~Gy} \\
\text { or } 3 \times 10 \mathrm{~Gy} \text { ) }\end{array}$ & & \\
\hline \multirow[t]{2}{*}{ Katz et al. [27] } & \multirow[t]{2}{*}{2007} & \multirow[t]{2}{*}{ Mets } & \multirow[t]{2}{*}{174} & \multirow[t]{2}{*}{$7-20$} & $30-55$ Gy & \multirow[t]{2}{*}{$57 \%$ after 20 months } & \multirow{2}{*}{$\begin{array}{l}\text { Lesion diameter } \\
\text { ranged from } \\
0.6-12.2 \mathrm{~cm}\end{array}$} \\
\hline & & & & & median 48 Gy & & \\
\hline $\begin{array}{l}\text { Rusthoven et al. } \\
\text { [11] }\end{array}$ & 2009 & Mets & 63 & 3 & $36-60$ Gy & $95 \%, 92 \%$ after 1 and 2 years & Phase-1/II study \\
\hline \multirow[t]{2}{*}{ Lee et al. [12] } & \multirow[t]{2}{*}{2009} & \multirow[t]{2}{*}{ Mets } & \multirow[t]{2}{*}{68} & \multirow[t]{2}{*}{6} & $27.7-60 \mathrm{~Gy}$ & $71 \%$ after 1 year & Phase-I study \\
\hline & & & & & median 41.8 Gy & & \\
\hline Van der Pool & 2010 & Mets & 31 & 3 & 12.5 Gy $(n=29)$ & $74 \%$ after 2 years & Grade III toxicities \\
\hline el dl. [ZU] & & & & & 15 Gy $(n=2)$ & & vere mepatic \\
\hline $\begin{array}{l}\text { Goodman et al. } \\
\text { [21] }\end{array}$ & 2010 & $\begin{array}{l}\text { Mets and } \\
\text { PLC }\end{array}$ & 40 & 1 & $18-30 \mathrm{~Gy}$ & $77 \%$ after 1 year & Phase-I study \\
\hline Rule et al. [28] & 2011 & Mets & 37 & 3 or 5 & $30-60$ Gy & $56 \%, 89 \%, 100 \%$ for 30,50 and $60-$ & Phase-I study \\
\hline & & & & & $\begin{array}{l}(30 \mathrm{~Gy} / 3 \mathrm{fx}, 50 \text { and } \\
60 \mathrm{~Gy} \text { in } 5 \mathrm{fx} \text { ) }\end{array}$ & Gy atter 2 years & \\
\hline Chang et al. [29] & 2011 & Mets & 65 & $1-6$ & $\begin{array}{l}\text { 22-60 Gy, median } \\
42 \text { Gy }\end{array}$ & $67 \%, 55 \%$ after 1 and 2 years & \\
\hline $\begin{array}{l}\text { Vautravers-Dewas } \\
\text { et al. [41] }\end{array}$ & 2011 & Mets & 42 & $3-4$ & $\begin{array}{l}40 \mathrm{~Gy} / 4 \mathrm{fx} \\
45 \mathrm{~Gy} / 3 \mathrm{fx}\end{array}$ & $86 \%$ after 2 years & \\
\hline Lanciano et al. & 2012 & Mets and & 30 & 3 or 5 & 79.2-180 Gy10 & $75 \%, 57 \%$ with BED10 >100 Gy & \\
\hline [40] & & & & & (66-150 Gy BED2) & after 1 and 2 years & \\
\hline This study & 2013 & Mets & 138 & 1 & $\begin{array}{l}\text { 10-30 Gy, median } \\
24 \text { Gy }\end{array}$ & $\begin{array}{l}87 \%, 69 \% \text { and } 59 \% \text { after } 6,12 \\
\text { and } 18 \text { months }\end{array}$ & \\
\hline
\end{tabular}

$\mathrm{HCC}$ without cirrhosis, and $\mathrm{HCC}<4 \mathrm{~cm}$ with cirrhosis were mostly treated with $3 \times 12.5 \mathrm{~Gy}$. Patients with $\mathrm{HCC} \geq 4 \mathrm{~cm}$ and cirrhosis received $5 \times 5$ Gy or $3 \times 10 \mathrm{~Gy}$. Gy Gray, CRC colorectal carcinoma, mets metastases, Pts. Patients, Pt. patient, DLT Dose-limiting toxicity, PLC Primary Liver cancer, fx fractions, LC Local Control.

approximately $90 \%$ and higher for CRC patients after 3-fraction SBRT, when doses of 45-48 Gy (BED) are applied $[29,41]$.

As a summary of available studies it be may be concluded that SBRT for liver metastasis leads to a 1- and 2-year local control of approximately $60-100 \%$ depending on patient group and fractionation scheme (recently reviewed by [35]). With regard to these data, our data reported in the present manuscript fit well in the range of reported data, confirming 12- and 18-months PFS rates of $70 \%$ and $59 \%$; however, in our group, patients presented with heterogeneous primary tumors, pretreatments, comorbidities and lesion characteristics. In comparison to many prospective studies, this dataset represents more a "real-life" scenario reflecting the clinical situation in a large oncology setting, with many competing treatment options. Additionally, the data confirms safety of the method in this group of patients, also 
for larger lesions in heavily pretreated patients. However, while reporting these real-life data, limitations of such an analysis must be kept in mind, such as some patients being lost-to-follow-up, or some data limitations due to the retrospective nature of the report.

The most analysed patient group of SBRT treated liver metastasis are patients with metastases derived from colorectal cancer. In several studies outcome of this patient group was relatively worse compared to other primary tumors which also can be confirmed by our analysis with 1-year local control rates of $67 \%$ for CRC compared to $90 \%$ for breast cancer patients [12,42]. One possible explanation of this observation may be the fact that CRC patients are often heavily pre-treated with several chemotherapy regimens and may therefore develop a cross resistance to ionizing radiation; moreover, due to the prior chemotherapeutic regimens patients are referred at a later stage of their disease, which might also explain the reduced outcome in CRC patients.

With increasing lesion volume safety concern with single fraction treatments become evident. Thus, multifraction schedules using 3-6 fractions may provide a better risk-benefit profile. However median lesion size of irradiated metastases certainly varies among different studies. While some authors report tumor size with the longest diameter or volume, others analysed the planning target volume, as we did in our study. Notably some authors found a dose-volume relationship [11,12] whereas our analysis failed to support a dependency of PTV and tumor response. Recent reports of other groups also failed to show a dependency between size and LC $[29,40,41]$.

Future studies in this field will elucidate the benefit of more (tumor-) adaptive radiotherapeutic procedures. Using highly conformal image-guided radiotherapy intrahepatic tumors can be irradiated with smaller safety margins, thus normal liver tissue can be prevented from radiation damage. For this purpose, e.g. fiducial markers are implanted in proximity of the target lesion and can be visualized by computed tomography or $\mathrm{x}$-ray images as a tumor surrogate to assure its correct position during treatment. New technologies such as gating and tracking of target lesions depend on the breathing phase and are correlated with the dose application [43-45].

Finally many retrospective studies and phase-I/-II clinical trials on SBRT have shown a high local control rate of intrahepatic metastases while avoiding severe therapyrelated complications in patients not suitable for resection. Best results were achieved with hypofractionated regimens and overall dose above 40 Gy in selected patient groups. The role of radiation therapy for the treatment of patients with liver metastases should therefore be re-defined and kept in mind in interdisciplinary treatment decisions. Further clinical evaluation, preferentially in randomized settings comparing to surgery of other locally ablative techniques, will further elucidate the full potential of SBRT in patients with liver metastases, especially in the subgroup of oligometastasized patients. Nevertheless prospective randomized clinical trials (RCT) comparing different local ablative therapies, e.g. TACE/ RFA and SBRT, are still lacking. According to this issue most recently Hoyer et al. initiated a multi-institutional RCT comparing RFA and SBRT for hepatic oligometastasis (1-4) (RAS01-Trial, NCT01233544) [35].

\section{Conclusion}

Our analysis of a large retrospectively evaluated monoinstitutional patient group who was treated with single-dose SBRT for liver metastases clearly shows a good local control rate. Many of these patients had more than one intrahepatic lesion or suffered from multiple metastases during treatment. Moreover there were different underlying primary tumors with impact on local control. In summary the analysis provides further evidence of the efficacy of highly conformal radiation, serving a basis for additionally radiotherapeutic improvements or a rationale for randomized trials with other locally ablative treatments or surgery. The dataset supports the use of SBRT in liver lesions, also in heavily pretreated patients or with larger lesions, with a convincing safety profile and sufficient lesion control probability.

\section{Competing interests}

The authors declare that they have no competing interests.

\section{Authors' contributions}

$\mathrm{KH}, \mathrm{HH}, \mathrm{TW}, \mathrm{JD}, \mathrm{SK}$ and SEC were responsible for patient treatment and care. $\mathrm{KH}, \mathrm{HH}, \mathrm{SK}$ and JD established the SRS methods. DH and $\mathrm{KH}$ collected the patients' data. JLB performed all statistical analyses. DH collected the data and wrote the manuscript. DH, KH, SR, TW, HH, JD and SEC contributed to the analysis of data and revised the manuscript. SEC conceived the study, helped to write and finalized the manuscript. All authors helped with the interpretation of the data, read and approved the final manuscript.

\section{Author details}

'Department of Radiation Oncology, University Hospital Center Heidelberg, INF 400, Heidelberg 69120, Germany. ${ }^{2}$ Institute of Medical Biometry and Informatics, University Hospital Heidelberg, INF 305, Heidelberg 69120, Germany. ${ }^{3}$ Klinik für Radioonkologie, University of Heidelberg, INF 40069120 , Heidelberg, Germany.

Received: 5 May 2013 Accepted: 7 July 2013

Published: 9 July 2013

\section{References}

1. Bengmark S, Hafstrom L: The natural history of primary and secondary malignant tumors of the liver I. the prognosis for patients with hepatic metastases from colonic and rectal carcinoma by laparotomy. Cancer 1969, 23(1):198-202.

2. Dawson LA, Ten Haken RK: Partial volume tolerance of the liver to radiation. Semin Radiat Oncol 2005, 15(4):279-283.

3. Rees M, Tekkis PP, Welsh FK, O'Rourke T, John TG: Evaluation of long-term survival after hepatic resection for metastatic colorectal cancer: a multifactorial model of 929 patients. Ann Surg 2008, 247(1):125-135.

4. Chua TC, Saxena A, Liauw W, Chu F, Morris DL: Hepatic resection for metastatic breast cancer: a systematic review. Eur J Cancer 2011, 47(15):2282-2290 
5. Small R, Lubezky N, Ben-Haim M: Current controversies in the surgical management of colorectal cancer metastases to the liver. IMAJ 2007, 9(10):742-747

6. Pawlik TM, Schulick RD, Choti MA: Expanding criteria for resectability of colorectal liver metastases. Oncologist 2008, 13(1):51-64

7. Machi J, Oishi AJ, Sumida K, Sakamoto K, Furumoto NL, Oishi RH, Kylstra JW: Long-term outcome of radiofrequency ablation for unresectable liver metastases from colorectal cancer: evaluation of prognostic factors and effectiveness in first- and second-line management. Cancer J 2006 12(4):318-326

8. Martin RC, Robbins K, Tomalty D, O'Hara R, Bosnjakovic P, Padr R, Rocek M, Slauf F, Scupchenko A, Tatum C: Transarterial chemoembolisation (TACE) using irinotecan-loaded beads for the treatment of unresectable metastases to the liver in patients with colorectal cancer: an interim report. World J Surg Oncol 2009, 7:80.

9. Bertot LC, Sato M, Tateishi R, Yoshida H, Koike K: Mortality and complication rates of percutaneous ablative techniques for the treatment of liver tumors: a systematic review. Eur Radiol 2011, 21(12):2584-2596.

10. Solbiati L, Livraghi T, Goldberg SN, lerace T, Meloni F, Dellanoce M, Cova L, Halpern EF, Gazelle GS: Percutaneous radio-frequency ablation of hepatic metastases from colorectal cancer: long-term results in 117 patients. Radiology 2001, 221(1):159-166.

11. Rusthoven KE, Kavanagh BD, Cardenes H, Stieber W, Burri SH, Feigenberg SJ, Chidel MA, Pugh TJ, Franklin W, Kane M, et al: Multi-institutional phase I/II trial of stereotactic body radiation therapy for liver metastases. J Clin Oncol 2009, 27(10):1572-1578.

12. Lee MT, Kim JJ, Dinniwell R, Brierley J, Lockwood G, Wong R, Cummings B, Ringash J, Tse RV, Knox JJ, et al: Phase I study of individualized stereotactic body radiotherapy of liver metastases. J Clin Oncol 2009, 27(10):1585-1591.

13. Habermehl D, Debus J, Ganten T, Ganten MK, Bauer J, Brecht IC, Brons S, Haberer T, Haertig M, Jaekel O, et al: Hypofractionated carbon ion therapy delivered with scanned ion beams for patients with hepatocellular carcinoma - feasibility and clinical response. Radiat Oncol 2013, 8(1):59.

14. Herfarth KK, Debus J, Lohr F, Bahner ML, Rhein B, Fritz P, Hoss A, Schlegel W, Wannenmacher MF: Stereotactic single-dose radiation therapy of liver tumors: results of a phase I/II trial. J Clin Oncol 2001, 19(1):164-170.

15. Wulf J, Hadinger U, Oppitz U, Thiele W, Ness-Dourdoumas R, Flentje M: Stereotactic radiotherapy of targets in the lung and liver. Strahlentherapie und Onkologie: Organ der Deutschen Rontgengesellschaft [et al.] 2001, 177(12):645-655

16. Schefter TE, Kavanagh BD, Timmerman RD, Cardenes HR, Baron A, Gaspar LE: A phase I trial of stereotactic body radiation therapy (SBRT) for liver metastases. Int J Radiat Oncol Biol Phys 2005, 62(5):1371-1378.

17. Hoyer M, Roed H, Traberg Hansen A, Ohlhuis L, Petersen J, Nellemann H, Kiil Berthelsen A, Grau C, Aage Engelholm S, Von der Maase H: Phase II study on stereotactic body radiotherapy of colorectal metastases. Acta Oncol 2006, 45(7):823-830.

18. Kavanagh BD, Schefter TE, Cardenes HR, Stieber VW, Raben D, Timmerman RD, McCarter MD, Burri S, Nedzi LA, Sawyer TE, et al: Interim analysis of a prospective phase I/II trial of SBRT for liver metastases. Acta Oncol 2006, 45(7):848-855.

19. Mendez Romero A, Wunderink W, Hussain SM, De Pooter JA, Heijmen BJ, Nowak PC, Nuyttens JJ, Brandwijk RP, Verhoef C, ljzermans JN, et al: Stereotactic body radiation therapy for primary and metastatic liver tumors: a single institution phase i-ii study. Acta Oncol 2006, 45(7):831-837.

20. van der Pool AE, Mendez Romero A, Wunderink W, Heijmen BJ, Levendag PC, Verhoef C, ljzermans JN: Stereotactic body radiation therapy for colorectal liver metastases. Br J Surg 2010, 97(3):377-382.

21. Goodman KA, Wiegner EA, Maturen KE, Zhang Z, Mo Q, Yang G, Gibbs IC, Fisher GA, Koong AC: Dose-escalation study of single-fraction stereotactic body radiotherapy for liver malignancies. Int J Radiat Oncol Biol Phys 2010, 78(2):486-493.

22. Herfarth KK, Debus J, Lohr F, Bahner ML, Fritz P, Hoss A, Schlegel W, Wannenmacher MF: Extracranial stereotactic radiation therapy: set-up accuracy of patients treated for liver metastases. Int J Radiat Oncol Biol Phys 2000, 46(2):329-335.

23. Bundschuh RA, Andratschke N, Dinges J, Duma MN, Astner ST, Brugel M, Ziegler SI, Molls M, Schwaiger M, Essler M: Respiratory gated [18F]FDG $\mathrm{PET} / \mathrm{CT}$ for target volume delineation in stereotactic radiation treatment of liver metastases. Strahlentherapie und Onkologie: Organ der Deutschen Rontgengesellschaft [et al.] 2012, 188(7):592-598.

24. Gong GZ, Yin Y, Xing LG, Guo YJ, Liu T, Chen J, Lu J, Ma C, Sun T, Bai T, et al: RapidArc combined with the active breathing coordinator provides an effective and accurate approach for the radiotherapy of hepatocellular carcinoma. Strahlentherapie und Onkologie: Organ der Deutschen Rontgengesellschaft [et al.] 2012, 188(3):262-268.

25. Fumagalli I, Bibault JE, Dewas S, Kramar A, Mirabel X, Prevost B, Lacornerie T, Jerraya $H$, Lartigau $E$ : A single-institution study of stereotactic body radiotherapy for patients with unresectable visceral pulmonary or hepatic oligometastases. Radiat Oncol 2012, 7:164.

26. Dewas S, Bibault JE, Mirabel X, Fumagalli I, Kramar A, Jarraya H, Lacornerie T, Dewas-Vautravers C, Lartigau E: Prognostic factors affecting local control of hepatic tumors treated by stereotactic body radiation therapy. Radiat Oncol 2012, 7:166.

27. Katz AW, Carey-Sampson M, Muhs AG, Milano MT, Schell MC, Okunieff P: Hypofractionated stereotactic body radiation therapy (SBRT) for limited hepatic metastases. Int J Radiat Oncol Biol Phys 2007, 67(3):793-798.

28. Rule W, Timmerman R, Tong L, Abdulrahman R, Meyer J, Boike T, Schwarz RE, Weatherall P, Chinsoo Cho L: Phase I dose-escalation study of stereotactic body radiotherapy in patients with hepatic metastases. Ann Surg Oncol 2011, 18(4):1081-1087.

29. Chang DT, Swaminath A, Kozak M, Weintraub J, Koong AC, Kim J, Dinniwell R, Brierley J, Kavanagh BD, Dawson LA, et al: Stereotactic body radiotherapy for colorectal liver metastases: a pooled analysis. Cancer 2011, 117(17):4060-4069

30. Lohr F, Debus J, Frank C, Herfarth K, Pastyr O, Rhein B, Bahner ML, Schlegel W, Wannenmacher M: Noninvasive patient fixation for extracranial stereotactic radiotherapy. Int J Radiat Oncol Biol Phys 1999, 45(2):521-527.

31. Dawson LA, Normolle D, Balter JM, McGinn CJ, Lawrence TS, Ten Haken RK: Analysis of radiation-induced liver disease using the lyman NTCP model. Int J Radiat Oncol Biol Phys 2002, 53(4):810-821.

32. Emami B, Lyman J, Brown A, Coia L, Goitein M, Munzenrider JE, Shank B, Solin $L$, Wesson M: Tolerance of normal tissue to therapeutic irradiation. Int J Radiat Oncol Biol Phys 1991, 21(1):109-122.

33. Ingold JA, Reed GB, Kaplan HS, Bagshaw MA: Radiation hepatitis. Am J Roentgenol Radium Ther Nucl Med 1965, 93:200-208.

34. Olsen CC, Welsh J, Kavanagh BD, Franklin W, McCarter M, Cardenes HR Gaspar LE, Schefter TE: Microscopic and macroscopic tumor and parenchymal effects of liver stereotactic body radiotherapy. Int J Radiat Oncol Biol Phys 2009, 73(5):1414-1424.

35. Hoyer M, Swaminath A, Bydder S, Lock M, Mendez Romero A, Kavanagh B, Goodman KA, Okunieff P, Dawson LA: Radiotherapy for liver metastases: a review of evidence. Int J Radiat Oncol Biol Phys 2012, 82(3):1047-1057.

36. Jaffe BM, Donegan WL, Watson F, Spratt JS Jr: Factors influencing survival in patients with untreated hepatic metastases. Surg Gynecol Obstet 1968, 127(1):1-11

37. Wagner JS, Adson MA, Van Heerden JA, Adson MH, Ilstrup DM: The natural history of hepatic metastases from colorectal cancer. a comparison with resective treatment. Ann Surg 1984, 199(5):502-508.

38. Scheele J, Altendorf-Hofmann A, Grube T, Hohenberger W, Stangl R, Schmidt K: Resection of colorectal liver metastases. what prognostic factors determine patient selection? Der Chirurg; Zeitschrift fur alle Gebiete der operativen Medizen 2001, 72(5):547-560.

39. Jenkins LT, Millikan KW, Bines SD, Staren ED, Doolas A: Hepatic resection for metastatic colorectal cancer. Am Surg 1997, 63(7):605-610.

40. Lanciano R, Lamond J, Yang J, Feng J, Arrigo S, Good M, Brady L: Stereotactic body radiation therapy for patients with heavily pretreated liver metastases and liver tumors. Frontiers in oncology 2012, 2:23.

41. Vautravers-Dewas C, Dewas S, Bonodeau F, Adenis A, Lacornerie T, Penel N, Lartigau E, Mirabel X: Image-guided robotic stereotactic body radiation therapy for liver metastases: is there a dose response relationship? Int $J$ Radiat Oncol Biol Phys 2011, 81(3):e39-e47.

42. Milano MT, Katz AW, Schell MC, Philip A, Okunieff P: Descriptive analysis of oligometastatic lesions treated with curative-intent stereotactic body radiotherapy. Int J Radiat Oncol Biol Phys 2008, 72(5):1516-1522.

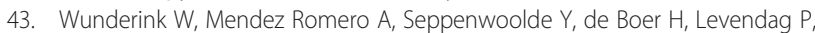
Heijmen B: Potentials and limitations of guiding liver stereotactic body radiation therapy set-up on liver-implanted fiducial markers. Int J Radiat Oncol Biol Phys 2010, 77(5):1573-1583 
44. Seppenwoolde Y, Wunderink W, Wunderink-van Veen SR, Storchi P, Mendez Romero A, Heijmen BJ: Treatment precision of image-guided liver SBRT using implanted fiducial markers depends on marker-tumour distance. Phys Med Biol 2011, 56(17):5445-5468.

45. Oshiro Y, Okumura T, Ishida M, Sugahara S, Mizumoto M, Hashimoto T, Yasuoka K, Tsuboi K, Sakae T, Sakurai H: Displacement of hepatic tumor at time to exposure in end-expiratory-triggered-pulse proton therapy. Radiother Oncol 2011, 99(2):124-130.

doi:10.1186/1748-717X-8-175

Cite this article as: Habermehl et al:: Single-dose radiosurgical treatment for hepatic metastases - therapeutic outcome of 138 treated lesions

from a single institution. Radiation Oncology 2013 8:175.

\section{Submit your next manuscript to BioMed Central and take full advantage of:}

- Convenient online submission

- Thorough peer review

- No space constraints or color figure charges

- Immediate publication on acceptance

- Inclusion in PubMed, CAS, Scopus and Google Scholar

- Research which is freely available for redistribution 